\title{
Targeting Interleukin-17A - An Orchestrator of Neutrophil Mobilisation in the Lungs
}

\author{
Anders Lindén*
}

Lung Immunology Group, Department of Internal Medicine/Respiratory Medicine and Allergology, Institute of Medicine, Sahlgrenska Academy at the University of Gothenburg, Bruna Stråket 11B, Sahlgrenska University Hospital, S-413 45, Gothenburg, Sweden

\begin{abstract}
This presentation briefly summarizes the immunology and the pathology of the $\mathrm{T}$ cell cytokine interleukin-17A (IL-17A) in the lungs and addresses the potential of IL-17A as a pharmacotherapeutical target. Accumulating experimental and clinical evidence suggests that IL-17A is of importance for coordinating the adaptive and the innate components of pulmonary host defence in mammals. This evidence also suggests that IL-17 is produced by several subsets of T cells, including the T helper-17 (Th-17) subset. Until now, IL-17A has emerged mainly as an orchestrator of the local accumulation and activity of neutrophils; a role that IL-17A plays by inducing the release of C-X-C chemokines, colony-stimulating factors and IL-6. Even though its true role may be more diverse, the proposed role of IL-17A is relevant not only for pulmonary host defence against bacteria but also for inflammatory conditions in the lungs, such as severe asthma, chronic obstructive pulmonary disease, cystic fibrosis, and lung allograft rejection. From an immunological point-of-view, IL-17A's position at the interface of adaptive and innate immunity, is intriguing. It forwards the possibility that intervention targeting IL-17A can provide new therapy against inflammatory lung disorders related to poor endogenous control of local neutrophils.
\end{abstract}

Keywords: Lung disease, therapy, neutrophil, IL-17, T cell.

\section{INTRODUCTION}

The protein that was to be named interleukin-17A (IL17A) was initially named cytotoxic T lymphocyte associated antigen 8 (CTLA8) in the original publication by Rouvier and co-workers in 1993 [1]. Since then, IL-17A has become the focus of more than 1,500 scientific publications and is now the best known member of the interleukin-17 family of cytokines [2-6]. Interestingly, IL-17A is likely to coordinate the adaptive and the innate components of host defence in mammals and it may play its main role in several organs by orchestrating the mobilisation of neutrophils [2-7]. Moreover, the discovery of IL-17A has led to the identification of a previously unknown subset of IL-17producing $\mathrm{T}$ helper cells in 2005 ; the Th-17 subset $[4,5,8,9]$. Notably, the characterisation of this Th-17 subset has challenged the classic "Th-1/Th-2 paradigm" and complicated the view of mammalian host defence. More recent studies on the Th-17 subset in animal models and in patients now implicate that IL-17A from Th-17 cells can play an important role in inflammatory conditions in the lungs, even though clinical trials of this concept are still lacking [4,5,8-10]. This review article summarizes the current knowledge about the immunology, the pathology and the potential utility of therapeutically targeting IL-17A in the lungs.

*Address correspondence to this author at the Lung Immunology Group, Department of Internal Medicine/Respiratory Medicine and Allergology, Institute of Medicine, Sahlgrenska Academy at the University of Gothenburg, Bruna Stråket 11B, Sahlgrenska University Hospital, S-413 45, Gothenburg, Sweden; Tel: +46 707 552529; Fax: +46 31 824904;

E-mail: anders.linden@gu.se

\section{IMMUNOLOGY}

\section{Molecular Characteristics}

The human homodimeric protein IL-17A has a molecular size of approximately $35 \mathrm{kDa}$; with each monomer including 155 amino acids in humans $[1,2,11,12]$. Notably, IL-17A was first identified as a rodent cDNA transcript, obtained from a T-lymphocyte hybridoma [1]. The molecular characteristics of the IL-17 family of cytokines includes a canonical cystein knot fold of $\beta$-strands, disulphide linkages and a conserved amino acid sequence close to the C-terminal [13]. As indicated from mice, rats and humans, IL-17A is very well conserved between species, in particular around the glucosylation site of the cytokine. Currently, IL-17B, -C, $\mathrm{D},-\mathrm{F}$ and the heterodimer IL-17A/F are all classified as IL17 family members [2,13-19]. In contrast, the cytokine that was previously named IL-17E has now been re-named IL-25 because this cytokine has a more "esoinophilic" functional profile [2,13-19]. Among the IL-17 cytokines, IL-17F is believed to be the one most similar to IL-17A and this monomer can actually form a heterodimer with the IL-17A monomer [2,9,13-19].

\section{Receptor Signalling}

The IL-17 receptor subtypes display a unique structure and no homology with previously identified cytokine receptor families [20,21]. Interleukin-17 RA, the archetype IL-17 receptor protein is a type I membrane protein, consisting of a 293 amino acid extracellular domain, a 21 amino acid trans-membrane domain and a 521 amino acid cytoplasmic tail. This particular receptor protein is expressed in many different cell types in humans and mice $[20,21]$. So 
far, four additional IL-17 receptor protein subtypes have been added to IL-17RA and these are named IL17RB, -C, -D and $\mathrm{E}[12,16,22]$. More recently, it has been suggested that IL-17RB protein can serve as a receptor not only for IL-17B but also for IL-17E when formed as a heteromeric receptor complex with IL-17RA [2,12,16,22,23]. Just like IL-17RA, all known IL-17 receptors proteins are type I transmembrane proteins, displaying significant alternative splicing [12].

In early studies, it was demonstrated that IL-17 signals at its receptor at low concentrations, with relatively low affinity, and because of this, it was assumed that there are additional receptor molecules; molecules that are required to facilitate IL-17 signalling [13,20,21]. In support of this, there is now data suggesting that effective IL-17-signaling does require a heteromeric receptor complex consisting of IL17RA and IL-17RC [24,25]. Collectively, published studies suggests that, after ligation of IL-17A to this receptor complex, a specific adaptor protein, Act1, is involved in the activation of down-stream signalling molecules, including the kinase TAK1 and the E3 ubiquitin ligase TRAF6, [9,2427]. These signalling molecules, as well as some mitogenactivated protein [MAP] kinases, functionally link IL-17A to the down-stream activation of transcription factors, including nuclear factor- $k \mathrm{~B}$ and CCAAT/enhancer binding Protein- $\beta$ $[25,26,28,29]$. The receptor signalling for IL-17A may also involve janus-activated kinase $[9,25,30]$.

Interestingly, it has been proposed that IL-17F as well as the heterodimer IL-17 A/F signal through the heteromeric receptor complex consisting of IL-17RA and IL-17RC [24,25,31-33]. Moreover, there might be a species difference between humans and mice for the receptor binding affinities $[33,34]$. In humans, IL-17A binds with comparable affinities to both IL-17RA and IL-17RC, but IL-17F binds to IL-17RC much stronger than to IL-17RA whereas, in mice, IL-17A binds to IL-17RA with much higher affinity than to IL17RC.

\section{Interleukin-17-Producing Cells in the Lungs}

We still do not understand the full nature of IL-17Aproducing cells in the lungs of humans and other mammals [9]. This means that it remains to be determined whether the majority of IL-17A-producing cells in humans lungs have the typical characteristics of "Th-17 cells", the postulated T helper cell subset that has been predicted to be critical for the production IL-17A [1,7-11]. Interestingly, Th-17 cells in humans display both similarities and differences, when compared with those in mice, but correspondingly conclusive studies in human lungs are lacking [35]. In fact, the current knowledge on IL-17-producing cells in human lungs is quite rudimentary.

Ivanov and co-workers have previously demonstrated immunoreactivity for IL-17A protein in a subset of relatively small, mononuclear cells from bronchoalveolar (BA) lavage samples harvested in healthy volunteers after exposure to organic dust [36]. The referred research group have also demonstrated that exposure to organic dust increase mRNA for IL-17A protein in BAL cells harvested under the referred conditions. In a preceding study on this model of severe neutrophilic inflammation, the same research group demonstrated a substantial increase in free, soluble IL-17 protein [37]. Thus, these results suggest that there are "lymphoid" cells within the human BA space that are capable of producing IL-17A protein. The fact that there is a correlation between messenger RNA for IL-17A and CD3 $\gamma$ in cells from induced sputum from patients with moderate to severe asthma, is compatible with these "lymphoid" cells in the BA space being T cells [38].

In contrast to the work on neutrophilic inflammation caused by organic dust, two previously published studies on patients with asthma have claimed that eosinophils account for the production of IL-17A protein in human airways $[39,40]$. Notably, though, none of these studies on asthma demonstrate the release of free, soluble IL-17A protein in isolated eosinophils in vitro.

There is interesting information from animal models as well. Systemic depletion of the CD4 and/or CD8 subsets of $\mathrm{T}$ cells prior to infection with the gram-negative bacterium Klebsiella pneumoniae in the lungs of mice in vivo, results in a marked decrease of IL-17 protein in BAL samples [41]. Moreover, when cultured in vitro, the CD4 but not the CD8 subset does respond to IL-23, an up-stream IL-17stimulating cytokine, when stimulated in vitro, when using BAL cells from mice primed with endotoxin exposure in the airways in vivo [42]. The more specific characteristics of these CD4 cells remain unknown, however. Even more intriguing, mice that have been infected with Mycobacteria in the lungs display $\gamma \delta \mathrm{T}$ cells that produce IL-17 in the lungs $[43,44]$. Moreover, a particular subset of invariant natural killer cells, a subset lacking the NK1.1 marker, does produce IL-17A protein after stimulation with synthetic ligands or with endotoxin in the lungs in vivo [45]. Clearly, we need novel studies that explore IL-1 $\beta$, IL-2, IL-6, IL-21, IL-23, IL-27 and tumor growth-transforming factor- $\beta$ in the lung context; cytokines believed to be critical for the regulation of "Th-17 subset" [8-10].

\section{Cellular Effects of IL-17A in the Lungs}

Based upon the published evidence, it seems most likely that IL-17A produces its neutrophil-accumulating effect in an indirect manner, by inducing the production and release of neutrophil mobilizing factors from stromal cells [2,5$7,9,10]$. Thus, in vitro data on chemotaxis of human blood neutrophils demonstrates that IL-17A per se does not cause chemotaxis for these cells [45]. In contrast, stimulation of human bronchial epithelial cells with IL-17A induces production and release of the neutrophil-recruiting $\mathrm{C}-\mathrm{X}-\mathrm{C}$ chemokines, including IL-8, granulocyte chemotactic protein-2 and growth-related oncogene- $\alpha$ in vitro and macrophage inflammatory protein-2 in vivo [46-51]. Moreover, conditioned medium from IL-17-stimulated human bronchial epithelial cells increases chemotaxis of human blood neutrophils and this particular effect is blocked after pre-treatment of the conditioned medium with a specific neutralizing IL-8 antibody [47]. Interestingly, several studies forward evidence that mitogen-activated protein [MAP] kinases are involved in mediating these chemokine responses to IL-17A [48,49,51]. Of potential therapeutic interest, the IL-17-induced release of GRO- $\alpha$ and GCP-2 is attenuated by glucocorticosteroids [49], whereas there is conflicting data on this for IL-8 [49,50]. In analogy with the case in bronchial epithelial cells, venous endothelial 
cells, lung fibroblasts and airway smooth muscle cells from humans and other mammals respond to IL-17A stimulation by releasing C-X-C chemokines [41,46,52-55].

Interleukin-6, a neutrophil-activating cytokine, is also released by structural cells such as bronchial epithelial cells and fibroblast in response to stimulation with IL-17A in vitro and probably also in vivo [47-50,56,57]. This is also true for the colony-stimulating factors, granulocyte colonystimulating factor and granulocyte macrophage colonystimulating factor [50,58].

Several experimental studies on mice and rats demonstrate that local stimulation with IL-17A causes a local accumulation of neutrophils in the BA space of these models in vivo [46,56,59-62]. It has also been demonstrated that the neutrophil-accumulating effect of IL-17A is selective, dose-dependent and long-lasting [46,58,59]. Interestingly, an induced over-expression of endogenous IL17A protein causes neutrophil accumulation in the BA space of mice as well [63]. In line with this, mice lacking IL-17 receptors are less capable of accumulating neutrophils after stimulation with a bacterial pathogen in the BA space than the corresponding control mice [62]. Also, the fact that pretreatment with a neutralizing anti-IL-17A antibody attenuates the IL-17A-induced accumulation of neutrophils in the BA space of rats is compatible with the effect being protein-specific [46].

In terms of chronic inflammatory lung disease and airway remodelling, it is of particular interest that IL-17A can cause local accumulation of proteases $[2,6,7,9]$. Indeed, it has been proven that local stimulation with IL-17A does increase the local activity of neutrophil elastase and matrix metalloproteinase- 9 in the BA space in vivo, in rats and mice respectively [60,61]. Importantly, IL-17A can increase myeloperoxidase in the BA space as well, at least in rats in vivo [60]. However, the mechanisms may differ in sensitized airways, because when endogenous IL-17A is blocked prior to allergen challenge in mice in vivo, this blockade decreases the percentage of MMP-9-positive neutrophils in the BA space after allergen challenge [64].

\section{Host Defence}

Importantly, the involvement of IL-17A in host defence is yet to confirm in humans and this is also true for the lungs $[7,9,10]$. In contrast, the experimental evidence from studies on mouse models is solid and clearly indicates an important role of IL-17A in host defence of the lungs in this species $[2,7,9,65]$. Thus, it has repeatedly been shown that local administration of endotoxin from $E$ coli increases the concentration of IL-17A protein in the BA space of mice in vivo $[56,66,67]$. Data from a study by Miyamoto and coworkers suggests that endogenous IL-17 is critical for the sustained but not for the early phase of the local neutrophil response [56]. Interestingly, local stimulation with endotoxin in the airways increases the archetype Th-17stimulating cytokine IL-23 in inflammatory cells from the BA space and in lung tissue and IL-23 protein per se causes neutrophil accumulation in the BA space [42]. Notably, the latter effect is attenuated when endogenous IL-17 is blocked with a neutralizing antiobody. Of particular importance, Ye and co-workers have demonstrated that a lack of the receptor molecule IL-17RA leads to an increased mortality in pneumonia for mice after exposure to live Klebsiella pneumonie in the BA space [65]. This negative "clinical outcome" is associated with a concomitant reduction in local neutrophils, compared with control mice. There is now supportive evidence from mouse models of infection with bacterial species such as Pseudomonas aureginosa, Bordetella pertussis, Mycoplasma pneumoniae and Streptococcus pneumonie as well $[9,68,69]$.

\section{PATHOLOGY}

We still do not know whether IL-17A really plays a causative role in inflammatory lung disease of humans $[4,9,10]$. However, there is accumulating evidence for an involvement of IL-17A in human lung disease. Currently, the strongest case is that for asthma.

\section{Asthma}

Important early work on IL-17A in patients with asthma was published by Chakir and co-workers [40]. Their study demonstrates a marked, relative increase in the number of cells that are immunorectivity for IL-17A protein in bronchial biopsies from patients with moderate to severe asthma, compared with mild asthma. In line with this, there are now studies demonstrating that IL-17-protein is increased in BA lavage fluid, sputum, and blood from patients with asthma $[39,40,70]$. It is of particular interest that, collectively, the referred studies suggest that there is no major increase in the concentration of IL-17A in patients with mild to moderate asthma, compared with healthy control subjects, because this implicates that the local increase in IL-17A is liked to a special phenotype of severe asthma; possibly associated with local accumulation of neutrophils $[6,7,9,10]$. On the other hand, a recent study comparing the "principal component analysis" of patients with chronic airflow obstruction with those that have intermittent airflow obstruction, actually claims that IL-17A is among the dominant variables in the latter group [71]. Clearly, this claim warrants further investigation. In further support for the involvement of IL-17A and neutrophils in asthma, the messenger RNA for IL-17A and the chemokine IL-8, respectively, is increased in cells from induced sputum of human patients with asthma [38]. Moreover, in the same patients, the level of IL-17 mRNA does correlates with the percentage of neutrophils in sputum samples [38].

In line with what has been documented in human patients with asthma, the results from two independent studies on mouse models of airway allergy support a role for endogenous IL-17A in mediating neutrophil accumulation $[61,65]$. In principle, both studies show that the blocking of endogenous IL-17A with a neutralizing antibody prior to allergen challenge attenuates the early neutrophil accumulation in the BA space following after the same challenge. In addition, one of these studies shows that the referred blockade of endogenous IL-17A prior to allergen challenge does reduce the relative number of accumulated MMP-9-expressing neutrophils in the BA space. The latter may have pathogenic bearing, because it suggests that IL$17 \mathrm{~A}$ has an impact on neutrophil activity in acute, allergic airway inflammation.

There is also indirect evidence for the involvement of IL17A in asthma and airway allergy; evidence for an 
involvement of IL-17A in bronchial hyperreactivity. It is well-known that bronchial hyperreactivity is linked to asthma, even though not synonymous to it. It is therefore of interest that there is evidence that the local concentration of IL-17A protein in sputum samples does correlate with airway reactivity to methacholine in human patients with either asthma or chronic bronchitis [72]. In line with this finding in humans, allergen-induced airway hyperreactivity to methacholine in mice is less pronounced in a mouse strain lacking endogenous IL-17A protein [73]. Notably, a recent experimental study has focused on this issue and addressed it in relation to the importance of Th-17 cells and neutrophils in a mouse model of airway allergy [74]. The study does suggest that local allergen sensitisation primes more of a Th-17 than a Th-2 response, in contrast to systemic sensitisation via the peritoneal cavity. According to the same study, Th-17 cells actually home to the BA space where they release IL-17A and when endogenous IL-17A is lacking, there is less allergen-induced increase in airway reactivity to metacholine [74]. Notably, the same study also indicates that even though neutrophils are required but not sufficient for the allergen-induced increase in airway reactivity.

\section{Chronic Obstructive Pulmonary Disease}

Currently, there is only one published study assessing IL17A in chronic obstructive pulmonary disease [75]. This study forwards data that shows an increased immunoreactivity for IL-17A protein in the bronchial submucosa in smokers with and without airflow obstruction [75]. In support of this, there are two independent studies on mice that include data suggesting an increase of IL-17A protein in the lungs after exposure to tobacco smoke in vivo [76,77].

\section{Cystic Fibrosis}

There are two published studies on human patients suggesting the involvement of IL-17A in the pathogenesis of cystic fibrosis $[78,79]$. These two studies show an increase in the concentration of IL-17A, as well as in its up-stream regulating cytokine $\mathrm{IL}-23$, in BA lavage and/or in sputum samples harvested during exacerbations of cystic fibrosis. However, the samples were harvested from patients colonised with Pseudomonas aureginosa and the controls were healthy subjects, so there is uncertainty with reference to what the conditions are like in patients with cystic fibrosis during stable clinical conditions.

\section{Lung Allograft Rejection}

Vanaudenaerde and co-workers forwarded early evidence that IL-17A is involved in acute rejection of lung allografts in humans [80]. Their study demonstrated that IL-17A in BA lavage samples can be increased at the messenger RNA and the protein level, during acute allograft rejection. There is also one experimental study on rats in vivo indicating that collagen type V-specific lymphocytes mediate lung allograft rejection, with a concomitant increase in messenger RNA for IL-17A locally at the site of rejection [81].

\section{STRATEGIES FOR THERAPEUTICALLY TARGET- ING IL-17A}

The current understanding of mammalian immunology suggests that "up-stream" cytokines such as IL-6, IL-15, IL23 , tumor-growth-transforming factor- $\beta$ and tumor necrosis factor bear the potential to influence IL-17A production in $\mathrm{T}$ cells in the lungs and in other organs $[2-5,10]$. In addition, there is autocrine influence of IL-21 [2-5,10]. The induced IL-17A production, in turn, stimulates the subsequent production of "down-stream" neutrophil-mobilising cytokines including IL-6, IL-8 and colony-stimulating factors; factors that all exert direct actions on neutrophils $[2-5,10]$. This implicates that there are three principal strategies for therapeutically targeting IL-17A: 1) up-stream of it; 2) at the level of the cytokine per se; and 3) down-stream of it [10]. An overview of these strategies is presented in Fig. (1); where drugs of key interest are listed.

It should be noted that none of the therapeutic strategies addresses in Fig. (1) have yet been tested in inflammatory lung disease of human patients. However, targeting upstream cytokines, such as IL-23 and tumor necrosis factor,

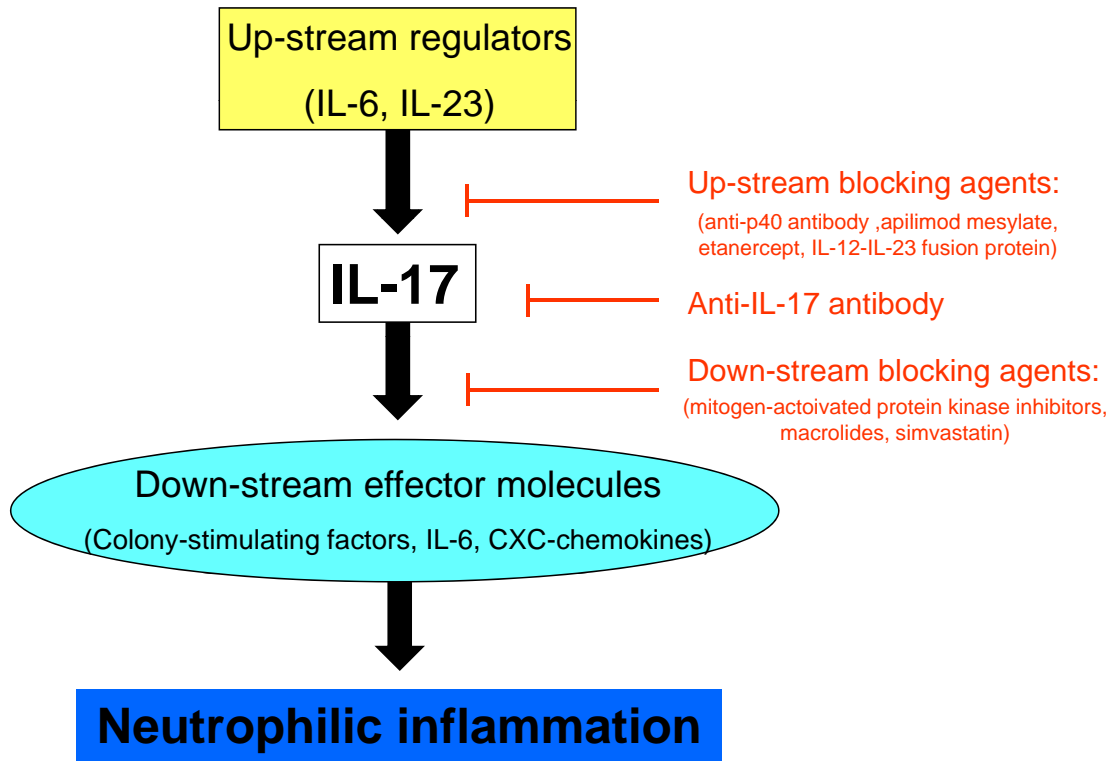

Fig. (1). Principal levels of targeting IL-17 signalling. Modified, with permission, from [10]. 
seems very feasible, since a monoclonal, neutralizing antibody against the p40 subunit of IL-23 and IL-12 is currently being evaluated in clinical trials on patients with Morbus Chron [10,81,82]. As an alternative to this antibody, there is at least one drug inhibiting the transcription of IL-23 and IL-12 (apilimod mesylate) as well as an IL-12 - IL-23 fusion protein that reduces IL-23-signalling [10]. Hypothetically, targeting IL-17A per se may be the most specific strategy, though, and targeting down-stream events may be the least specific strategy.

\section{CONCLUSIONS}

A solid clinical rationale for therapeutically targeting IL17A in human lung disease is not yet established. The main reason for this is the relatively small number of published studies on the immunology and pathology of IL-17A in human patients; studies that until now have been conducted on relatively small patient materials. However, given what we now know about the experimental immunology and pathology of IL-17A in animal models, it can be speculated that targeting the neutrophil-orchestrating cytokine IL-17A will be therapeutically beneficial in lung diseases characterized by $\mathrm{T}$ helper cell activity and an excess accumulation and activation of neutrophils. Whether this should include subgroups of patients with acute or chronic lung allograft rejection, asthma, chronic bronchitis, chronic obstructive pulmonary disease, cystic fibrosis acute or chronic lung allograft rejection is in need of further study.

\section{ACKNOWLEDGEMENTS}

This work was financially supported by the University of Gothenburg, the Swedish Heart-Lung Fund (Project No 20070471) and the Swedish Science Council (Project No K2008-57X-09048-19-3). The critical comments on this manuscript by Elin Silverpil, M.Sc, are gratefully acknowledged.

\section{ABBREVIATIONS}

$\mathrm{BA}=$ bronchoalveolar

IL $\quad=$ interleukin

RNA $=$ ribonucleic acid

\section{REFERENCES}

[1] Rouvier, E.; Luciani, M.F.; Mattéi, M.G.; Denizot, F.; Golstein, P. CTLA-8, cloned from an activated $\mathrm{T}$ cell, bearing AU-rich messenger RNA instability sequences, and homologous to a herpesvirus saimiri gene. J. Immunol., 1993, 150, 5445-5456.

[2] Kolls J.K. \& Lindén, A. Interleukin-17 family members and inflammation. Immunity, 2004, 21, 467-476.

[3] Matsuzaki, G. ; Umemura, M. Interleukin-17 as an effector molecule of innate and acquired immunity against infections. Microbiol Immunol., 2007, 51(12), 1139-47.

[4] Dong, C. TH17 cells in development: an updated view of their molecular identity and genetic programming. Nat. Rev. Immunol., 2008, 8[5], 337-48.

[5] Ouyang, W.; Kolls, J.K.; Zheng, Y. The biological functions of T helper 17 cell effector cytokines in inflammation. Immunity., 2008, 28(4), 454-67.

[6] Lindén, A.; Hoshino, H.; Laan. M. Airway neutrophils and interleukin-17. Eur. Respir. J., 2000, 15, 973-977.

[7] Lindén A.; Laan, M.; Anderson, GP. Neutrophils, interleukin-17A and lung disease. Eur. Respir. J., 2005, 25, 159-172.

[8] Wynn TA. T(H)-17: a giant step from $\mathrm{T}(\mathrm{H})-1$ and $\mathrm{T}(\mathrm{H})-2$. Nat. Immunol., 2005, 6(11), 1069-70.
[9] Ivanov, S.; Lindén, A. Th-17 cells in the lungs? Exp. Rev. Respir. Med., 2007, 1(2), 279-293

[10] Ivanov, S.; Lindén, A. IL-17 as a drug target in human disease. Trends Pharm. Sci., 2009, 30(2), 95-103.

[11] Yao, Z.; Painter, S.L.; Fanslow, W.C.; Ulrich, D.; Macduff, B.M.; Spriggs, M.K.; Armitage, R.J. Human IL-17: a novel cytokine derived from T cells. J. Immunol., 1995, 155, 5483-5486.

[12] Moseley, T.A.; Haudenschild, D.R.; Rose, L.; Reddi, A.H. Interleukin-17 family and IL-17 receptors. Cytokine Growth Factor Rev., 2003, 14, 155-174.

[13] Hymowitz, S.G.; Filvaroff, E.H.; Yin, J.P.; Lee, J.; Cai, L.; Risser, P.; Maruoka, M.; Mao, W.; Foster, J.; Kelley, R.F.; Pan, G.; Gurney, A.L.; de Vos, A.M.; Starovasnik, M.A.. IL-17s adopt a cystine knot fold: structure and activity of a novel cytokine, IL$17 \mathrm{~F}$, and implications for receptor binding. EMBO J., 2001, 20 [19], 5332-5341.

[14] Li, H.; Chen, J.; Huang, A.; Stinson, J.; Heldens, S.; Foster, J.; Dowd, P.; Gurney, A.L.; Wood, W.I. Cloning and characterization of IL-17B and IL-17C, two new members of the IL-17 cytokine family. Proc. Natl. Acad. Sci. USA, 2000, 97(2), 773-8.

[15] Starnes, T.; Broxmeyer, H.E.; Robertson, M.J.; Hromas, R. Cutting edge: IL-17D, a novel member of the IL-17 family, stimulates cytokine production and inhibits hemopoiesis. J. Immunol., 2002, 169, 642-646.

[16] Lee, J.; Ho, W.H.; Maruoka, M.; Corpuz, R.T.; Baldwin, D.T.; Foster, J.S.; Goddard, A.D.; Yansura, D.G.; Vandlen, R.L.; Wood, W.I.; Gurney, A.L. IL-17E, a novel proinflammatory ligand for the IL-17 receptor homolog IL-17Rh1. J. Biol. Chem., 2001, 169(1), 4430-4435.

[17] Kim, M.R.; Manoukian, R.; Yeh, R.; Silbiger, SM.; Danilenko, D.M.; Scully, S.; Sun, J.; DeRose, M.L.; Stolina, M.; Chang, D.; Van, G.Y.; Clarkin, K.; Nguyen, H.Q.; Yu, Y.B.; Jing, S.; Senaldi, G.; Elliott, G.; Medlock, E.S. Transgenic overexpression of human IL-17E results in eosinophilia, B-lymphocyte hyperplasia, and altered antibody production. Blood, 2002, 100, 2330-2340.

[18] Starnes, T.; Robertson, M.J.; Sledge, G.; Kelich, S.; Nakshatri, H.; Broxmeyer, H.E.; Hromas, R. Cutting edge: IL-17F, a novel cytokine selectively expressed in activated $\mathrm{T}$ cells and monocytes, regulates angiogenesis and endothelial cell cytokine production. $J$. Immunol., 2001, 167, 4137-4140.

[19] Chang, S.H.; Dong, C. A novel heterodimeric cytokine consisting of IL-17 and IL-17F regulates inflammatory responses. Cell Res., 2007, 17(5), 435-440.

[20] Yao, Z; Fanslow WC, Seldin MF, Rousseau AM, Painter SL, Comeau MR, Cohen JI, Spriggs MK. Herpesvirus Saimiri encodes a new cytokine, IL-17, which binds to a novel cytokine receptor. Immunity, 1995, 3, 811-821.

[21] Yao, Z.; Spriggs MK, Derry JM, Strockbine L, Park LS, VandenBos T, Zappone JD, Painter SL, Armitage RJ. Molecular characterization of the human interleukin (IL)-17 receptor. Cytokine, 1997, 9, 794-800.

[22] Shi, Y.; Ullrich, S.J.; Zhang, J.; Connolly, K.M; Grzegorzewski, K.J.; Barber, M.C.; Wang, W.; Wathen, K.; Hodge, V.; Fisher, C.L.; Olsen, H.; Ruben, S.M.; Knyazev, I.; Cho, Y.H.; Kao, V.; Wilkinson, K.A.; Carrell, J.A.; Ebner, R. A novel cytokine receptor-ligand pair. Identification, molecular characterization, and in vivo immunomodulatory activity. J. Biol. Chem., 2000, 275, 19167-19176.

[23] Rickel, E.A.; Siegel, L.A.; Yoon, B.R.; Rottman, J.B.; Kugler, D.G.; Swart, D.A.; Anders, P.M.; Tocker, J.E.; Comeau, M.R.; Budelsky, A.L. Identification of functional roles for both IL-17RB and IL-17RA in mediating IL-25-induced activities. J. Immunol., 2008, 181, 4299-4310.

[24] Toy, D.; Kugler, D.; Wolfson, M.; Vanden Bos, T.; Gurgel, J.; Derry, J.; Tocker, J.; Peschon, J. Cutting edge: interleukin 17 signals through a heteromeric receptor complex. J. Immunol., 2006 177, 36-39.

[25] Lindén, A. A role for the cytoplasmic adaptor protein Act1 in mediating IL-17 signaling. Science STKE, 2007, 398, re4.

[26] Qian, Y.; Liu, C.; Hartupee, J.; Altuntas, C.Z.; Gulen, M.F.; JaneWit, D.; Xiao, J.; Lu, Y.; Giltiay, N.; Liu, J.; Kordula, T.; Zhang, Q.W.; Vallance, B.; Swaidani, S.; Aronica, M.; Tuohy, V.K.; Hamilton, T.; Li, X. The adaptor Act1 is required for interleukin 17-dependent signaling associated with autoimmune and inflammatory disease. Nat. Immunol., 2007, 8(3), 247-56. 
[27] Chang, S.H.; Park, H.; Dong, C. Act1 adaptor protein is an immediate and essential signaling component of interleukin-17 receptor. J. Biol. Chem., 2006, 281, 35603-35607.

[28] Ruddy, M. J.; Wong, G.C.; Liu, X.K.; Yamamoto, H.; Kasayama, S.; Kirkwood, K.L.; Gaffen, S.L. Functional cooperation between interleukin-17 and tumor necrosis factor-alpha is mediated by CCAAT/enhancer-binding protein family members. J. Biol. Chem., 2004, 279, 2559-2567.

[29] Shen, F.; Hu, Z.; Goswami, J.; Gaffen, S.L. Identification of common transcriptional regulatory elements in interleukin-17 target genes. J. Biol. Chem., 2006, 281, 24138-24148.

[30] Huang, F.; Kao, C.Y.; Wachi, S.; Thai, P.; Ryu, J.; Wu, R. Requirement for both JAK-mediated PI3K signaling and ACT1/TRAF6/TAK1-dependent NF-kappaB activation by IL-17A in enhancing cytokine expression in human airway epithelial cells. J. Immunol., 2007, 179(10), 6504-13.

[31] Rong, Z.; Cheng, L.; Ren, Y.; Li, Z.; Li, Y.; Li, X.; Li H, Fu, X.Y.; Chang, Z. Interleukin- $17 \mathrm{~F}$ signaling requires ubiquitination of interleukin-17 receptor via TRAF6. Cell. Signal., 2007, 19(7), 1514-20.

[32] Wright, J. F.; Bennett, F.; Li, B.; Brooks, J.; Luxenberg, D.P.; Whitters, M.J.; Tomkinson, K.N.; Fitz, L.J.; Wolfman, N.M.; Collins, M.; Dunussi-Joannopoulos, K.; Chatterjee-Kishore, M.; Carreno, B.M. The human IL-17F/IL-17A heterodimeric cytokine signals through the IL-17RA/IL-17RC receptor complex. J. Immunol., 2008, 181(4), 2799-2805.

[33] Ishigame, H.; Kakuta, S.; Nagai, T.; Kadoki, M.; Nambu, A.; Komiyama, Y.; Fujikado, N.; Tanahashi, Y.; Akitsu, A.; Kotaki, H.; Sudo, K.; Nakae, S.; Sasakawa, C.; Iwakura, Y. Differential roles of interleukin-17A and $-17 \mathrm{~F}$ in host defense against mucoepithelial bacterial infection and allergic responses. Immunity, 2009, 30, 108-119.

[34] Kuestner, R.; Taft, D.W.; Haran, A.; Brandt, C.S.; Brender, T.; Lum, K.; Harder, B.; Okada, S.; Ostrander, C.D.; Kreindler, J.L.; Aujla, S.J.; Reardon, B.; Moore, M.; Shea, P.; Schreckhise, R.; Bukowski, T.R.; Presnell, S.; Guerra-Lewis, P.; Parrish-Novak, J.; Ellsworth, J.L.; Jaspers, S.; Lewis, K.E.; Appleby, M.; Kolls, J.K.; Rixon, M.;, West, J.W.; Gao, Z.; Levin, S.D.. Identification of the IL-17 receptor related molecule IL-17RC as the receptor for IL17F. J. Immunol., 2007, 179, 5462-5473.

[35] Annunziato, F.; Cosmi, L.; Liotta, F.; Maggi, E.; Romagnani, S. Human Th17 cells: are they different from murine Th17 cells?. Eur. J. Immunol., 2009, 39, 637-640.

[36] Ivanov, S.; Palmberg, L.; Venge, P.; Larsson, K.; Lindén A. Interleukin-17A mRNA and protein expression within cells from the human bronchoalveolar space after exposure to organic dust. Respir. Res., 2005, 6, 44.

[37] Laan, M.; Palmberg, L.; Larsson, K.; Lindén, A. Free, soluble IL17 protein during severe inflammation in human airways. Eur. Respir. J., 2002, 19, 534-537.

[38] Bullens M.A.D.; Truyen, E.; Coteur, L.; Dilissen, E.; Hellings, P.W.; Dupont, L.J.; Ceuppens, J.L. IL-17 mRNA in sputum of asthmatic patients: linking $\mathrm{T}$ cell driven inflammation and granulocytic influx? Respir. Res., 2006, 7, 135.

[39] Molet, S.; Hamid, Q.; Davoine, F.; Nutku, E.; Taha, R.; Pagé, N.; Olivenstein, R.; Elias, J.; Chakir, J. IL-17 is increased in asthmatic airways and induces human bronchial fibroblasts to produce cytokines. J. Allergy Clin. Immunol., 2001, 108, 430-438.

[40] Chakir, J.; Shannon, J.; Molet, S.; Fukakusa, M.; Elias, J.; Laviolette, M.; Boulet, L.P.; Hamid, Q. Airway remodelingassociated mediators in moderate to severe asthma: effect of steroids on TGF-beta, IL-11, IL-17, and type I and type III collagen expression. J. Allergy Clin. Immunol., 2003, 111, 1293-1298.

[41] Happel K.I.; Zheng, M.; Young, E.; Quinton, L.J.; Lockhart, E.; Ramsay, A.J.; Shellito, J.E.; Schurr, J.R.; Bagby, G.J.; Nelson, S.; Kolls, J.K. Cutting edge: roles of Toll-like receptor 4 and IL-23 in IL-17 expression in response to Klebsiella pneumoniae infection $J$. Immunol., 2003, 170, 4432-4436.

[42] Ivanov S.; Bozinovski, S.; Bossios, A.; Valadi, H.; Vlahos, R.; Malmhäll, C.; Sjöstrand, M.; Kolls, J.K.; Anderson, G.P.; Lindén, A. Functional relevance of the IL-23-IL-17 axis in lungs in vivo. Am. J. Respir. Crit. Care Med., 2007, 36(4), 442-51.

[43] Lockhart, E.; Green, A.M.; Flynn, J.L. IL-17 production is dominated by gammadelta $\mathrm{T}$ cells rather than CD4 $\mathrm{T}$ cells during Mycobacterium tuberculosis infection. J. Immunol., 2006, 177(7), 4662-9.
[44] Umemura, M.; Yahagi, A.; Hamada, S.; Begum, M.D.; Watanabe, H.; Kawakami, K.; Suda, T.; Sudo. K.; Nakae, S.; Iwakura, Y.; Matsuzaki, G. IL-17-mediated regulation of innate and acquired immune response against pulmonary Mycobacterium bovis bacille Calmette-Guerin infection. J. Immunol., 2007, 178, 3786-3796.

[45] Michel, M-L.; Keller, A.C.; Paget, C.; Fujio, M.; Trottein, F.; Savage, P.B.; Wong, C.H.; Schneider, E.; Dy, M.; Leite-deMoraes, M.C. Identification of an IL-17-producing NK1.1(neg) iNKT cell population involved in airway neutrophilia. J. Exp Med., 2007, 204, 995-1001.

[46] Laan, M.; Cui, Z.H.; Hoshino, H.; Lötvall, J.; Sjöstrand, M.; Gruenert, D.C.; Skoogh, B.-E.; Lindén, A. Neutrophil recruitment by human IL-17 via C-X-C chemokine release in the airways. $J$. Immunol., 1999, 162, 2347-2352.

[47] Fossiez, F., Djossou, O.; Chomarat, P.; Flores-Romo, L.; AitYahia, S.; Maat, C.; Pin, J.J.; Garrone, P.; Garcia, E.; Saeland, S.; Blanchard, D.; Gaillard, C.; Das Mahapatra, B.; Rouvier, E.; Golstein, P.; Banchereau, J.; Lebecque, S. T cell interleukin-17 induces stromal cells to produce proinflammatory and hematopoietic cytokines. J. Exp. Med., 1996, 183, 2593-2603.

[48] Kawaguchi, M.; Kokubu, F.; Kuga, H.; Matsukura, S.; Hoshino, H.; Ieki, K.; Imai, T.; Adachi, M.; Huang, S.K. Modulation of bronchial epithelial cells by IL-17. J. Allergy Clin. Immunol., 2001, 108, 804-809.

[49] Laan, M.; Lötvall, J.; Chung, K.F.; Lindén, A. IL-17-induced cytokine release in human bronchial epithelial cells in vitro: role of mitogen-activated protein (MAP) kinases. Br. J. Pharmacol., 2001, 133, 200-206.

[50] Jones, C.E.; Chan, K. Interleukin-17 stimulates the expression of interleukin-8, growth-related oncogene-alpha, and granulocytecolony-stimulating factor by human airway epithelial cells. Am. J. Respir. Cell Mol. Biol., 2002, 26, 748-753.

[51] Prause, O.; Laan, M.; Lötvall, J.; Lindén, A. Pharmacological modulation of interleukin-17-induced GCP-2-, GRO- $\alpha-$ and interleukin-8-release in human bronchial epithelial cells. Eur. J. Pharmacol., 2003, 462, 193-198.

[52] Numasaki, M.; Lotze, M.T.; Sasaki, H. Interleukin-17 augments tumor necrosis factor-alpha-induced elaboration of proangiogenic factors from fibroblasts. Immunol. Lett., 2004, 93, 39-43.

[53] Vanaudenaerde, B.M.; Wuyts, W.A.; Dupont, L.J.; Van Raemdonck, D.E.; Demedts, M.M.; Verleden, G.M. Interleukin-17 stimulates release of interleukin- 8 by human airway smooth muscle cells in vitro: a potential role for interleukin-17 and airway smooth muscle cells in bronchiolitis obliterans syndrome. J. Heart Lung Transplant., 2003, 22, 1280-1283.

[54] Dragon, S.; Rahman, M.S.; Yang, J, Unruh, H.; Halayko, A.J.; Gounni, A.S. IL-17 enhances IL-1beta-mediated CXCL-8 release from human airway smooth muscle cells Am. J. Physiol., Lung Cell. Mol. Physiol., 2007, 292(4), L1023-9.

[55] Henness, S.; van Thoor, E.; Ge, Q.; Armour, C.L.; Hughes, J.M.; Ammit, A.J. IL-17A acts via p38 MAPK to increase stability of TNF-alpha-induced IL-8 mRNA in human ASM. Am. J. Physiol. Lung Cell Mol. Physiol., 2006, 290(6), L1283-90.

[56] Miyamoto, M.; Prause, O.; Laan, M.; Sjöstrand, M.; Lötvall, J.; Lindén, A. Endogenous IL-17 as a mediator of neutrophil recruitment caused by endotoxin exposure in mouse airways. $J$. Immunology, 2003, 170, 4665-4672.

[57] Schwandner, R.; Yamaguchi, K.; Cao, Z. Requirement of tumor necrosis factor receptor-associated factor (TRAF)6 in interleukin 17 signal transduction. J. Exp. Med., 2000, 191, 1233-1239.

[58] Laan, M.; Prause, O.; Miyamoto, M.; Sjöstrand, M.; Hytönen, A.M.; Kaneko, T.; Lötvall, J.; Lindén, A. A role of GM-CSF in the accumulation of neutrophils in the airways caused by IL-17 and TNF-alpha. Eur. Respir. J., 2003, 21(3), 1-7.

[59] Hoshino, H.; Lötvall, J.; Skoogh, B.-E.; Lindén, A. Neutrophil recruitment by IL-17 into rat airways in vivo: role of tachykinins. Am. J. Respir. Crit. Care Med., 1999, 159, 1423-1428.

[60] Hoshino, H.; Laan, M.; Sjöstrand, M.; Lötvall, J.; Skoogh, B.-E.; Lindén, A. Increased elastase and myeloperoxidase activity associated with neutrophil recruitment by IL-17 in airways in vivo. J. Allergy Clin. Immunol., 2000, 105, 143-149.

[61] Hellings, P.W.; Kasran, A.; Liu, Z.; Vandekerckhove, P.; Wuyts, A.; Overbergh, L.; Mathieu, C.; Ceuppens, J.L. Interleukin-17 orchestrates the granulocyte influx into airways after allergen inhalation in a mouse model of allergic asthma. Am. J. Respir. Crit. Care Med., 2003, 28(1), 42-50. 
[62] Prause, O.; Bozinovski, S.; Anderson, G.P.; Lindén, A. Increased matrix metalloproteinase-9 concentration and activity after stimulation with interleukin-17 in mouse airways. Thorax., 2004, 59(4), 313-317.

[63] Ye, P.; Garvey, P.B.; Zhang, P.; Nelson, S.; Bagby, G.; Summer, W.R.; Schwarzenberger, P.; Shellito, J.E.; Kolls, J.K. Interleukin17 and lung host defense against Klebsiella pneumoniae infection. Am. J. Respir. Cell Mol. Biol., 2001, 25, 335-340

[64] Sergejeva, S.; Ivanov, S.; Lötvall, J.; Lindén, A. IL-17 as a recruitment and survival factor for airway macrophages in allergic airway inflammation. Am. J. Respir. Cell Mol. Biol., 2005, 33, 248253.

[65] Ye, P.; Rodriguez, F.H.; Kanaly, S.; Stocking, K.L.; Schurr, J.; Schwarzenberger, P.; Oliver, P.; Huang, W.; Zhang, P.; Zhang, J.; Shellito, J.E.; Bagby, G.J.; Nelson, S.; Charrier, K.; Peschon, J.J.; Kolls, J.K. Requirement of interleukin 17 receptor signaling for lung CXC chemokine and granulocyte colony-stimulating factor expression, neutrophil recruitment, and host defense. J. Exp. Med., 2001, 194, 519-528.

[66] Larsson, R.; Rocksén, D.; Lilliehöök, B.; Jonsson, A.; Bucht, A. Dose-dependent activation of lymphocytes in endotoxin-induced airway inflammation. Infect. Immun., 2000, 68(12), 6962-6969.

[67] Ferretti, S.; Bonneau O, Dubois GR, Jones CE, Trifilieff A. IL-17, produced by lymphocytes and neutrophils, is necessary for lipopolysaccharide-induced airway neutrophilia: IL-15 as a possible trigger. J. Immunol., 2003, 170, 2106-2112.

[68] Aujla, S.J.; Dubin, P.J.; Kolls, J.K. Interleukin-17 in pulmonary host defense. Exp. Lung Res., 2007, 33(10), 507-18.

[69] Dubin, P.J.; Kolls, J.K. IL-23 mediates inflammatory responses to mucoid Pseudomonas aeruginosa lung infection in mice. Am. J. Physiol. Lung Cell Mol. Physiol. 2007, 292(2), L519-528

[70] Sun, Y.C.; Zhou, Q,T,; Yao, W.Z. Sputum interleukin-17 is increased and associated with airway neutrophilia in patients with severe asthma. Chin Med. J. [Engl]., 2005, 118(11), 953-956.

[71] Kaminska, M.; Foley, S.; Maghn,i K.; Storness-Bliss, C.; Coxson, H.; Ghezzo, H.; Lemière, C.; Olivenstein, R.; Ernst, P.; Hamid, Q.; Martin, J. Airway remodeling in subjects with severe asthma with or without chronic persistent airflow obstruction. J. Allergy Clin. Immunol., 2009, 124, 45-51.

[72] Barczyk, A.; Pierzchala, W.; Sozañska, E. Interleukin-17 in sputum correlates with airway hyperresponsiveness to methacholine. Respir. Med., 2003, 97, 726-733.

[73] Nakae, S.; Komiyama, Y.; Nambu, A.; Sudo, K.; Iwase, M.; Homma, I.; Sekikawa, K.; Asano, M..; Iwakura, Y. Antigenspecific $\mathrm{T}$ cell sensitization is impaired in IL-17-deficient mice, causing suppression of allergic cellular and humoral responses. Immunity, 2002, 17, 375-387.

[74] Wilson, R.H.; Whitehead, G.S.; Nakano, H.; Free, M.E.; Kolls, J.K.; Cook, D.N. Allergic sensitization through the airway primes Th17-dependent neutrophilia and airway hyperresponsiveness. Am. J. Respir. Crit. Care Med., 2009, 180, 720-730.
[75] Di Stefano, A.; Caramori, G.; Gnemmi, I.; Contoli, M.; Vicari, C.; Capelli, A.; Magno, F.; D'Anna, S.E.; Zanini, A:; Brun, P.; Casolari, P.; Chung, K.F.; Barnes, P.J.; Papi, A.; Adcock, I.; Balbi, B. T helper type 17-related cytokine expression is increased in the bronchial mucosa of stable chronic obstructive pulmonary disease patients. Clin. Exp. Immunol., 2009, 157, 316-324.

[76] Van der Deen, M.; Timens, W.; Timmer-Bosscha, H.; van der Strate, B.W.; Scheper, R.J.; Postma, D.S.; de Vries, E.G.; Kerstjens, H.A. Reduced inflammatory response in cigarette smoke exposed Mrp1/Mdr1a/1b deficient mice. Respir. Res., 2007, 8, 49.

[77] Shen, F.; Zhao, M.W.; He, B.; Wang, Y.Z.; Yao, W.Z. The levels and clinical implications of induced sputum interleukin-17 in chronic obstructive pulmonary disease and asthma. Zhonghua Nei Ke Za Shi, 2004, 43, 888-890.

[78] Aujla, S.J.; Chan, Y.R.; Zheng, M.; Fei, M.; Askew, D.J.; Pociask, D.A.; Reinhart, T.A.; McAllister, F.; Edeal, J.; Gaus, K.; Husain, S.; Kreindler, J.L.; Dubin, P.J.; Pilewski, J.M.; Myerburg, M.M.; Mason, C.A.; Iwakura, Y.; Kolls, J.K. IL-22 mediates mucosal host defense against Gram-negative bacterial pneumonia. Nat. Med., 2008, 14(3), 275-281.

[79] McAllister, F.; Henry, A.; Kreindler, J.L.; Dubin, P.J.; Ulrich, L.; Steele, C.; Finder, J.D.; Pilewski, J.M.; Carreno, B.M.; Goldman, S.J.; Pirhonen, J.; Kolls, J.K. Role of IL-17A, IL-17F, and the IL17 receptor in regulating growth-related oncogene-alpha and granulocyte colony-stimulating factor in bronchial epithelium: implications for airway inflammation in cystic fibrosis. $J$. Immunol., 2005, 175, 404-412.

[80] Vanaudenaerde, B.M.; Dupont, L.J.; Wuyts, W.A.; Verbeken, E.K.; Meyts, I.; Bullens, D.M.; Dilissen, E.; Luyts, L.; Van Raemdonck, D.E.; Verleden, G.M. The role of interleukin-17 during acute rejection after lung transplantation. Eur. Respir. J., 2006, 27, 77987.

[81] Yoshida, S.; Haque, A.; Mizobuchi, T.; Iwata, T.; Chiyo, M.; Webb, T.J.; Baldridge, L.A.; Heidler, K.M.; Cummings, O.W.; Fujisawa, T.; Blum, J.S.; Brand, D.D.; Wilkes, D.S. Anti-type V collagen lymphocytes that express IL-17 and IL-23 induce rejection pathology in fresh and well-healed lung transplants. Am. J. Transplant., 2006, 6, 724-35.

[81] Mannon P.J.; Fuss, I.J.; Mayer, L.; Elson, C.O.; Sandborn, W.J.; Present, D.; Dolin, B.; Goodman, N.; Groden, C.; Hornung, R.L.; Quezado, M.; Yang, Z.; Neurath, M.F.; Salfeld, J.; Veldman, G.M.; Schwertschlag, U.; Strober, W. Anti-interleukin-12 antibody for active Crohn's disease. N. Engl. J. Med., 2004, 351, 2069-2079.

[82] Fuss, I.J.; Becker, C.; Yang, Z.; Groden, C.; Hornung, R.L.; Heller, F.; Neurath, M.F.; Strober, W.; Mannon, P.J. Both IL-12p70 and IL-23 are synthesized during active Crohn's disease and are downregulated by treatment with anti-IL-12 p40 monoclonal antibody. Inflamm. Bowel Dis., 2006, 12, 9-15.

(C) Anders Lindén; Licensee Bentham Open.

This is an open access article licensed under the terms of the Creative Commons Attribution Non-Commercial License (http://creativecommons.org/licenses/by-nc/3.0/) which permits unrestricted, non-commercial use, distribution and reproduction in any medium, provided the work is properly cited. 